[Article]

\title{
$\mathrm{Bi}_{2} \mathrm{MoO}_{6} / \mathrm{BiVO}_{4}$ 异质结的水热合成和可见光催化活性
}

\author{
林 雪 ${ }^{1, *}$ 郭晓宇 ${ }^{2}$ 王庆伟 ${ }^{2, *}$ 常利民 ${ }^{2}$ 翟宏菊 ${ }^{2}$ \\ ('吉林师范大学环境友好材料制备与应用教育部重点实验室, 吉林 四平 136000 ; \\ 2吉林师范大学化学学院, 吉林四平 136000)
}

\begin{abstract}
摘要: 采用一步水热法制备 $\mathrm{Bi}_{2} \mathrm{MoO}_{6} / \mathrm{BiVO}_{4}$ 复合光催化剂. 利用 $X$ 射线衍射 $(X R D)$ 、场发射扫描电子显微镜 (FESEM)、高分辨透射电子显微镜(HRTEM)等手段对其晶体结构和微观结构进行了表征. 结果表明, $\mathrm{Bi}_{2} \mathrm{MoO}_{6}$ 纳米粒子沉积在 $\mathrm{BiVO}_{4}$ 纳米片表面从而形成异质结结构. 紫外-可见漫反射光谱(UV-Vis DRS)表明所制备的 $\mathrm{Bi}_{2} \mathrm{MoO}_{6} / \mathrm{BiVO}_{4}$ 异质结较纯相 $\mathrm{Bi}_{2} \mathrm{MoO}_{6}$ 和 $\mathrm{BiVO}_{4}$ 对可见光吸收更强. 由于形成异质结结构及其光吸收性能使 $\mathrm{Bi}_{2} \mathrm{MoO}_{6} / \mathrm{BiVO}_{4}$ 光催化活性有较大提高. 可见光下 $(\lambda>420 \mathrm{~nm})$ 光催化降解罗丹明 $\mathrm{B}(\mathrm{RhB})$ 实验结果表明, $\mathrm{Bi}_{2} \mathrm{MoO}_{6} / \mathrm{BiVO}_{4}$ 光催化活性较纯相 $\mathrm{Bi}_{2} \mathrm{MoO}_{6}$ 和 $\mathrm{BiVO}_{4}$ 高. $\mathrm{Bi}_{2} \mathrm{MoO}_{6} / \mathrm{BiVO}_{4}$ 样品光催化性能提高的原因是 $\mathrm{Bi}_{2} \mathrm{MoO}_{6}$ 和 $\mathrm{BiVO}_{4}$ 形成异质结, 从而有效抑制光生电子-空穴对的复合, 增大了可见光吸收范围及比表面积.
\end{abstract}

关键词: $\mathrm{Bi}_{2} \mathrm{MoO}_{6} / \mathrm{BiVO}_{4} ;$ 复合材料; 纳米结构; 光催化活性

中图分类号: $\mathrm{O} 643$

\section{Hydrothermal Synthesis and Efficient Visible Light Photocatalytic Activity of $\mathrm{Bi}_{2} \mathrm{MoO}_{6} / \mathrm{BiVO}_{4}$ Heterojunction}

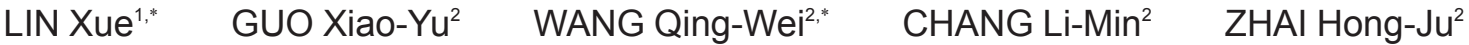 \\ ('Key Laboratory of Preparation and Application Environmentally Friendly Materials, Ministry of Education, \\ Jilin Normal University, Siping 136000, Jilin Province, P. R. China; ${ }^{2}$ College of Chemistry, Jilin Normal University, \\ Siping 136000, Jilin Province, P. R. China)
}

\begin{abstract}
A} \mathrm{Bi}_{2} \mathrm{MoO}_{6} / \mathrm{BiVO}_{4}$ photocatalyst with a heterojunction structure was synthesized by a one-pot hydrothermal method. Its crystal structure and microstructure were characterized by X-ray diffraction (XRD), field emission scanning electron microscopy (FESEM), and high-resolution transmission electron microscopy (HRTEM). The FESEM and HRTEM images indicated that $\mathrm{Bi}_{2} \mathrm{MoO}_{6}$ nanoparticles were loaded on the surface of $\mathrm{BiVO}_{4}$ nanoplates to form a heterojunction. The ultraviolet visible (UV-Vis) diffuse reflection spectra (DRS) showed that the resulting $\mathrm{Bi}_{2} \mathrm{MoO}_{6} / \mathrm{BiVO}_{4}$ heterojunction possessed more intensive absorption within the visible light range compared with pure $\mathrm{Bi}_{2} \mathrm{MoO}_{6}$ and $\mathrm{BiVO}_{4}$. These excellent structural and spectral properties endowed the $\mathrm{Bi}_{2} \mathrm{MoO}_{6} / \mathrm{BiVO}_{4}$ heterojunction with enhanced photocatalytic activity. It was found that the Rhodamine $\mathrm{B}$ $(\mathrm{RhB})$ degradation rate with $\mathrm{Bi}_{2} \mathrm{MoO}_{6} / \mathrm{BiVO}_{4}$ was higher than that with pure $\mathrm{BiVO}_{4}$ and $\mathrm{Bi}_{2} \mathrm{MoO}_{6}$ under visible light $(\lambda>420 \mathrm{~nm})$ by photocatalytic measurements. The enhanced photocatalytic performance of the $\mathrm{Bi}_{2} \mathrm{MoO}_{6} / \mathrm{BiVO}_{4}$ sample can be attributed to the improved separation efficiency of photogenerated hole-electron pairs generated by the heterojunction between $\mathrm{Bi}_{2} \mathrm{MoO}_{6}$ and $\mathrm{BiVO}_{4}$, intensive absorption within the visible light range, and high specific surface area.
\end{abstract}

Key Words: $\mathrm{Bi}_{2} \mathrm{MoO}_{6} / \mathrm{BiVO}_{4} ; \quad$ Composite material; Nanostructure; Photocatalytic activity

Received: June 30, 2014; Revised: September 4, 2014; Published on Web: September 5, 2014.

"Corresponding authors. LIN Xue, Email: jlsdlinxue@126.com; Tel: +86-15694349717; Fax: +86-434-3291890.

WANG Qing-Wei, Email: wqw611203@163.com.

The project was supported by the National Natural Science Foundation of China (21407059, 61308095) and Science Development Project of Jilin Province, China (20130522071JH, 20130102004JC, 20140101160JC).

国家自然科学基金(21407059, 61308095)和吉林省科技发展计划项目(20130522071JH, 20130102004JC, 20140101160JC)资助

(c) Editorial office of Acta Physico-Chimica Sinica 


\section{Introduction}

As the environment deteriorates, green chemistry has become a necessary requirement for the sustainable development of human society. Among the various green chemical techniques, semiconductor photocatalysis has emerged as one of the most promising technologies because it represents an easy way to utilize the energy of either natural sunlight or artificial indoor illumination. ${ }^{1-3}$ The semiconductor $\mathrm{TiO}_{2}$ is considered as one of the best photocatalysts for environmental remediation. ${ }^{4}$ However, the light response range and photo-efficiency of $\mathrm{TiO}_{2}$ are limited because of the wide band gap. ${ }^{5-7}$ Therefore, it is urgent to develop highly efficient visible-light driven photocatalysts for pollutants degradation. ${ }^{8,9}$ Recently, a lot of visible light driven photocatalysts containing bismuth for environmental treatment and/or water splitting have been reported, such as $\mathrm{BiVO}_{4},{ }^{10-12} \mathrm{Bi}_{4} \mathrm{Ti}_{3} \mathrm{O}_{12},{ }^{13}$ $\mathrm{Bi}_{2} \mathrm{WO}_{6}{ }^{14,15}$ and $\mathrm{Bi}_{2} \mathrm{MoO}_{6} \cdot{ }^{16}$ Among these candidates, monoclinic bismuth vanadate $\left(\mathrm{BiVO}_{4}\right)$ with a band gap of $2.4 \mathrm{eV}$ has attracted considerable attentions due to its photocatalytic activity under visible light irradiation. However, its high-rate recombination of electron $/$ hole $\left(\mathrm{e}^{-} / \mathrm{h}^{+}\right)$pair leads to the need of a sacrificial reagent to improve its photocatalytic performance. For instance, photocatalytic $\mathrm{O}_{2}$ evolution by $\mathrm{BiVO}_{4}$ could be improved in $\mathrm{AgNO}_{3}$ solution. ${ }^{17}$ Doping photocatalysts with foreign elements is an effective approach for the construction of visible- light-driven photocatalyst materials. ${ }^{18-20}$ However, these photocatalysts always suffer from the problems of the discrete doping levels and the low mobility of the carriers in the doping levels. Besides, the low doping quantity makes it difficult to absorb a sufficient quantity of visible light by transitions. With further development, $\mathrm{BiVO}_{4}$ photocatalyst was usually modified with other semiconductors in order to reduce the recombination chance. ${ }^{21,22}$

Recently, the formation of heterojunction by coupling of two semiconductors with narrow band gap has attracted special attentions as a novel strategy for overcoming two defects above of traditional photocatalysts. ${ }^{23-28}$ Given that both of two semiconductors possess narrow band gap, such a heterogeneous system allows photocatalyst to utilize more visible light than traditional photocatalysts. What is more, the recombination of photogenerated electron-hole pairs can be effectively suppressed through a charge transfer between two semiconductors. ${ }^{29}$ Despite these advantages of heterojunction, it is not easy to construct such a system because the energy levels of coupling semiconductors must be well-matched overlapping band-structures. Therefore, the key link of constructing a heterojunction is to seek narrow band gap semiconductors with well-matched band-structures. It has been found that the $\mathrm{Bi}_{2} \mathrm{MoO}_{6}$ can use the visible light with the appropriate band gap energy (ca $2.64 \mathrm{eV}) .{ }^{16}$ The conduction band potential $\left(E_{\mathrm{CB}}\right)$ of $\mathrm{Bi}_{2} \mathrm{MoO}_{6}$ is $-0.32 \mathrm{eV}$ (vs normal hydrogen electrode $(\mathrm{NHE}))$, which is more negative than that of $\mathrm{BiVO}_{4}\left(E_{\mathrm{CB}}=\right.$ $0 \mathrm{eV}(v s \mathrm{NHE})$ ), and the valence band energy $\left(E_{\mathrm{VB}}\right)$ level of $\mathrm{Bi}_{2} \mathrm{MoO}_{6}$ is $2.32 \mathrm{eV}$ (vs NHE), which is also more negative than that of $\mathrm{BiVO}_{4}\left(E_{\mathrm{VB}}=2.40 \mathrm{eV}(v s \text { NHE })\right)^{30,31}$ The matching of conduction band $(\mathrm{CB})$ and valence band $(\mathrm{VB})$ levels between
$\mathrm{Bi}_{2} \mathrm{MoO}_{6}$ and $\mathrm{BiVO}_{4}$ makes $\mathrm{Bi}_{2} \mathrm{MoO}_{6}$ to be a suitable material for constructing heterojunction with $\mathrm{BiVO}_{4}$.

Herein, the $\mathrm{Bi}_{2} \mathrm{MoO}_{6} / \mathrm{BiVO}_{4}$ composite photocatalyst with heterojunction structure was synthesized. Rhodamine $\mathrm{B}(\mathrm{RhB})$, which is a common toxic pollutant in industry effluent, was chosen as a probe to test photocatalytic activity of the composite sample. The mechanism of enhanced photocatalytic activity of this composite was also discussed.

\section{Experimental}

\subsection{Preparation of photocatalysts}

All chemicals were analytic grade and used without further purification. $\mathrm{Bi}\left(\mathrm{NO}_{3}\right)_{3} \cdot 5 \mathrm{H}_{2} \mathrm{O}(2 \mathrm{mmol})$ was firstly dissolved with $\mathrm{Na}_{2} \mathrm{MoO}_{4} \cdot 2 \mathrm{H}_{2} \mathrm{O}(1 \mathrm{mmol})$ or $\mathrm{NaVO}_{3} \cdot 2 \mathrm{H}_{2} \mathrm{O}(2 \mathrm{mmol})$ in $10 \mathrm{~mL}$ water. For synthesis of $\mathrm{Bi}_{2} \mathrm{MoO}_{6}$, the $\mathrm{pH}$ value of solution was adjusted to 3 by adding $1 \mathrm{~mol} \cdot \mathrm{L}^{-1} \mathrm{HNO}_{3}$, the mixture was then transferred into a $20 \mathrm{~mL}$ Teflon-lined stainless steel autoclave, and heated to $160{ }^{\circ} \mathrm{C}$ for $24 \mathrm{~h}$. After reaction, the obtained solid was washed with distilled water three times, and dried at $80{ }^{\circ} \mathrm{C}$ for 24 h. For synthesis of $\mathrm{BiVO}_{4}$, the $\mathrm{pH}$ value of solution was adjusted to 3 by adding $1 \mathrm{~mol} \cdot \mathrm{L}^{-1} \mathrm{HNO}_{3}$, the mixture was then transferred into a $20 \mathrm{~mL}$ Teflon-lined stainless steel autoclave, and heated to $180{ }^{\circ} \mathrm{C}$ for $24 \mathrm{~h}$. After reaction, the obtained solid was washed with distilled water three times, and dried at $80^{\circ} \mathrm{C}$ for $24 \mathrm{~h}$. For synthesis of $\mathrm{Bi}_{2} \mathrm{MoO}_{6} / \mathrm{BiVO}_{4}$ heterojunction, $\mathrm{Bi}\left(\mathrm{NO}_{3}\right)_{3} \cdot 5 \mathrm{H}_{2} \mathrm{O}(3$ mmol) and total $2 \mathrm{mmol} \mathrm{Na}_{2} \mathrm{MoO}_{4} \cdot 2 \mathrm{H}_{2} \mathrm{O}+\mathrm{NaVO}_{3}$ (molar ratio of Mo: $\mathrm{V}$ is $1: 1)$ were dissolved in $40 \mathrm{~mL}$ water. The $\mathrm{pH}$ value of the mixture was adjusted to 3 by adding $1 \mathrm{~mol} \cdot \mathrm{L}^{-1} \mathrm{HNO}_{3}$, and $1 \mathrm{~mL}$ glacial acetic acid was added as the buffer reagent. The mixture was then transferred into a $20 \mathrm{~mL}$ Teflon-lined stainless steel autoclave, and heated to $160{ }^{\circ} \mathrm{C}$ for $24 \mathrm{~h}$. After reaction, the obtained solid was washed with distilled water three times, and dried at $80{ }^{\circ} \mathrm{C}$ for $24 \mathrm{~h}$. The obtained product was named as $\mathrm{Bi}_{2} \mathrm{MoO}_{6} /$ $\mathrm{BiVO}_{4}-\mathrm{HT}$.

\subsection{Characterization of photocatalysts}

The crystal structures of the samples were characterized by Xray diffraction (XRD, Japan Rigaku D/max 2500) with $\mathrm{Cu} K_{\alpha}$ radiation. The morphologies and structure details of the as-prepared samples were detected by using a field emission scanning microscopy (FESEM, Japan JEOL JSM-6700F) and high-resolution transmission electron microscopy (HRTEM, Japan JEOL JEM-2100F). The chemical composition of the compound was determined by scanning electron microscope- X-ray energy dispersion spectrum (SEM-EDX, Japan JEOL JSM-6700F). The specific surface areas of the samples were measured through nitrogen adsorption BET method (BET/BJH Surface Area, 3H2000PS1). The optical properties were obtained by the photoluminescence (PL) measurement using HR800 LabRam Infinity Spectro photometer excited by a continuous He-Cd laser with a wavelength of $325 \mathrm{~nm}$ at a power of $50 \mathrm{~mW}$. X-ray photoelectron spectroscopy (XPS) analysis was performed with an ESCALab220i-XL electron spectrometer (VG Scientific, England) using $300 \mathrm{~W} \mathrm{Al} K_{\alpha}$ radiation. The UV-Vis diffuse reflectance spectra 
(DRS) were recorded for the dry-pressed disk sample using a scan UV-Vis spectrophotometer (UV-Vis, Japan Shimadzu UV-2550) equipped with an integrating sphere assembly.

\subsection{Photocatalytic activities}

The photocatalytic activities of the as-prepared samples were evaluated using $\mathrm{RhB}$ dye as a model compound. In experiments, the $\mathrm{RhB}$ dye solution $\left(0.005 \mathrm{mmol} \cdot \mathrm{L}^{-1}, 100 \mathrm{~mL}\right)$ containing 0.04 $\mathrm{g}$ of photocatalyst were mixed in a pyrex reaction glass. A $500 \mathrm{~W}$ Xe lamp $(\lambda>420 \mathrm{~nm})$ was used to provide visible light irradiation. A glass sheet was inserted between the lamp and the sample to filter out UV light $(\lambda<420 \mathrm{~nm})$. Prior to visible light illumination, the suspension was strongly magnetically stirred for $30 \mathrm{~min}$ in the dark for adsorption/desorption equilibrium. Then the solution was exposed to visible light irradiation under magnetic stirring. At given time intervals, about $4 \mathrm{~mL}$ of the suspension was periodically withdrawn and analyzed after centrifugation. The RhB concentration was analyzed by a UV-2550 spectrometer to record intensity of the maximum band at $552 \mathrm{~nm}$ in the UV-Vis absorption spectra.

\subsection{Active species trapping experiments}

For detecting the active species during photocatalytic reactivity, some sacrificial agents, such as tert-butanol $(t-\mathrm{BuOH})$, disodium ethylenediamine tetraacetic acid (EDTA-2Na) and 1,4-benzoquinone (BQ) were employed as the hydroxyl radical $\left(\mathrm{OH}^{\bullet}\right)$ scavenger, hole $\left(\mathrm{h}^{+}\right)$scavenger, and superoxide radical $\left(\mathrm{O}_{2}^{-}{ }^{-}\right)$ scavenger, respectively. The method was similar to the former photocatalytic property test with the addition of $2 \mathrm{mmol}$ of quencher in the presence of RhB.

\section{Results and discussion \\ 3.1 XRD analysis}

Fig.1 displays the XRD patterns of the prepared $\mathrm{BiVO}_{4}$, $\mathrm{Bi}_{2} \mathrm{MoO}_{6}$, and $\mathrm{Bi}_{2} \mathrm{MoO}_{6} / \mathrm{BiVO}_{4}$ composite. The diffraction peaks of $\mathrm{BiVO}_{4}$ sample can be assigned to the monoclinic structure of $\mathrm{BiVO}_{4}$ (JCPDS card No. 14-0688). This observation is further confirmed by the splitting of the peaks at $2 \theta=28.9^{\circ}, 30.6^{\circ}, 53.3^{\circ}$, which is characteristic of the monoclinic structure of $\mathrm{BiVO}_{4}$. As can be seen in the pattern of $\mathrm{Bi}_{2} \mathrm{MoO}_{6}$ sample, the diffraction peaks are identical to standard card (JCPDS card No. 21-0102). For the $\mathrm{Bi}_{2} \mathrm{MoO}_{6} / \mathrm{BiVO}_{4}$ composite, diffraction peaks at about $2 \theta=$

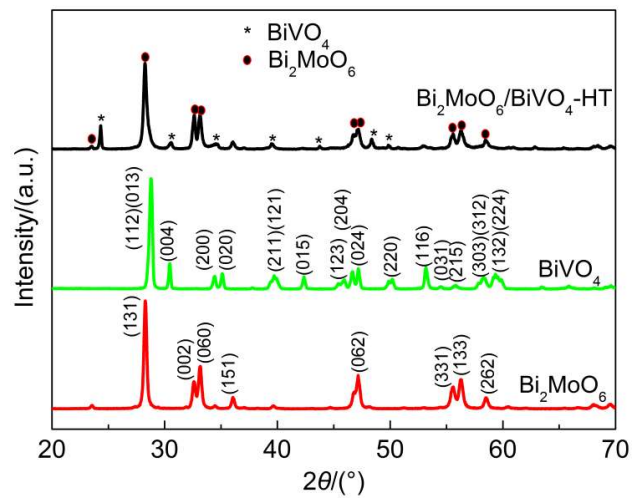

Fig.1 XRD patterns of $\mathrm{BiVO}_{4}, \mathrm{Bi}_{2} \mathrm{MoO}_{6}$, and $\mathrm{Bi}_{2} \mathrm{MoO}_{6} / \mathrm{BiVO}_{4}-\mathrm{HT}$ $30.6^{\circ}, 34.6^{\circ}, 39.4^{\circ}, 48.3^{\circ}, 49.9^{\circ}, 50.7^{\circ}$ can be perfectly indexed to $\mathrm{BiVO}_{4}$ (JCPDS card No. 14-0133). Besides, additional diffraction peaks with $2 \theta$ values of $28.2^{\circ}, 32.6^{\circ}, 33.2^{\circ}, 36.1^{\circ}, 47.2^{\circ}$, $55.6^{\circ}, 56.3^{\circ}$, and $58.5^{\circ}$ appeared, corresponding to $\mathrm{Bi}_{2} \mathrm{MoO}_{6}$ (JCPDS card No. 21-0102), respectively. These results reveal that the mixture of $\mathrm{BiVO}_{4}$ and $\mathrm{Bi}_{2} \mathrm{MoO}_{6}$ is the main existing form of $\mathrm{Bi}_{2} \mathrm{MoO}_{6} / \mathrm{BiVO}_{4}$ composite. The main peaks of $\mathrm{BiVO}_{4}$ are week in $\mathrm{Bi}_{2} \mathrm{MoO}_{6} / \mathrm{BiVO}_{4}$ composite, which may be associated with the relatively low crystallinity of $\mathrm{BiVO}_{4}$ crystals.

\subsection{XPS analysis}

XPS spectra for the $\mathrm{Bi}_{2} \mathrm{MoO}_{6} / \mathrm{BiVO}_{4}-\mathrm{HT}$ sample are presented to determine the oxidation state and elemental composition for each member of the composite (Fig.2). The Bi $4 f$ fine XPS spectrum of the sample is displayed in Fig.2a. XPS signals of $\mathrm{Bi}$ $4 f$ were observed at binding energies at about $163.38 \mathrm{eV}\left(\mathrm{Bi} 4 f_{7 / 2}\right)$ and $158.10 \mathrm{eV}\left(\mathrm{Bi} 4 f_{5 / 2}\right)$, ascribed to $\mathrm{Bi}^{3+}{ }^{32}$ The characteristic spinorbital splitting photoelectrons for Mo $3 d$ (232.00 and $235.15 \mathrm{eV}$ ) indicate a six-valent oxidation state for $\mathrm{Mo}^{6+}$ (Fig.2b). ${ }^{24}$ The peak at $515.95 \mathrm{eV}\left(\mathrm{V} 2 p^{3}\right)$ could be attributed to $\mathrm{V}$ of $\mathrm{VO}_{4}^{3-32}$ as shown in Fig.2c. The $\mathrm{O} 1 s$ peak is shown in Fig.2d, which was fitted into the peak centering at $530.06 \mathrm{eV}$ and mainly assigned to the oxygen in the prepared sample lattice. ${ }^{24}$ These results are agreed with the XRD data, further proving that the mixture of $\mathrm{Bi}_{2} \mathrm{MoO}_{6}$ and $\mathrm{BiVO}_{4}$ was formed.

\subsection{SEM and HRTEM observations}

The morphology and the micro-structure of the photocatalysts are illustrated in Fig.3. From Fig.3a, the $\mathrm{BiVO}_{4}$ exhibits a thin and plate-like morphology with average size of $2 \mu \mathrm{m}$ and thickness of $100 \mathrm{~nm}$, approximately. It can be seen that the shape of the $\mathrm{Bi}_{2} \mathrm{MoO}_{6}$ particle is spherical with average size of about $100 \mathrm{~nm}$ (Fig.3b). TEM image of $\mathrm{Bi}_{2} \mathrm{MoO}_{6}$ particle is shown in Fig.3c. It can also be observed that the morphology of $\mathrm{Bi}_{2} \mathrm{MoO}_{6}$ is nanospheres with average size of around $100 \mathrm{~nm}$. The morphology of the $\mathrm{Bi}_{2} \mathrm{MoO}_{6}$ will avail itself to contact with the $\mathrm{BiVO}_{4}$, increasing the join area of them. In addition, the $\mathrm{Bi}_{2} \mathrm{MoO}_{6} / \mathrm{BiVO}_{4}$ composite shows a sphere-on-plate structure, indicating a possibility of the heterojunction structure by covering $\mathrm{Bi}_{2} \mathrm{MoO}_{6}$ and $\mathrm{BiVO}_{4}$ particles to each other (as revealed in Fig.3d). Furthermore, the size of $\mathrm{BiVO}_{4}$ nanoplates in $\mathrm{Bi}_{2} \mathrm{MoO}_{6} / \mathrm{BiVO}_{4}$ composite is smaller than that of pure $\mathrm{BiVO}_{4}$. Fig.3e displays a magnified FESEM image of $\mathrm{Bi}_{2} \mathrm{MoO}_{6} / \mathrm{BiVO}_{4}$ composite. It can be observed that spherical $\mathrm{Bi}_{2} \mathrm{MoO}_{6}$ nanoparticles are highly dispersed on the surface of the $\mathrm{BiVO}_{4}$ nanoplates. Fig. $3 \mathrm{f}$ shows the HRTEM image of a typical $\mathrm{Bi}_{2} \mathrm{MoO}_{6} / \mathrm{BiVO}_{4}$ heterojunction photocatalyst. The two types of lattice fringes are clearly visible with a spacing of about 0.273 and $0.259 \mathrm{~nm}$, which correspond to the lattice spacing of the (010) plane of orthorhombic $\mathrm{Bi}_{2} \mathrm{MoO}_{6}$ and (020) lattice spacing of tetragonal $\mathrm{BiVO}_{4}$, respectively, which is well consistent with the EDX results. The HRTEM image of $\mathrm{Bi}_{2} \mathrm{MoO}_{6} / \mathrm{BiVO}_{4}$ reveals that $\mathrm{Bi}_{2} \mathrm{MoO}_{6}$ nanoparticles are deposited on the surface of $\mathrm{BiVO}_{4}$ nanoplates, coinciding with the above characterization results. EDX elemental microanalysis confirms $\mathrm{Bi}, \mathrm{V}, \mathrm{Mo}$, and $\mathrm{O}$ as major elements in the heterojunction. The molar ratio of $\mathrm{Mo} / \mathrm{V}$ is cal- 

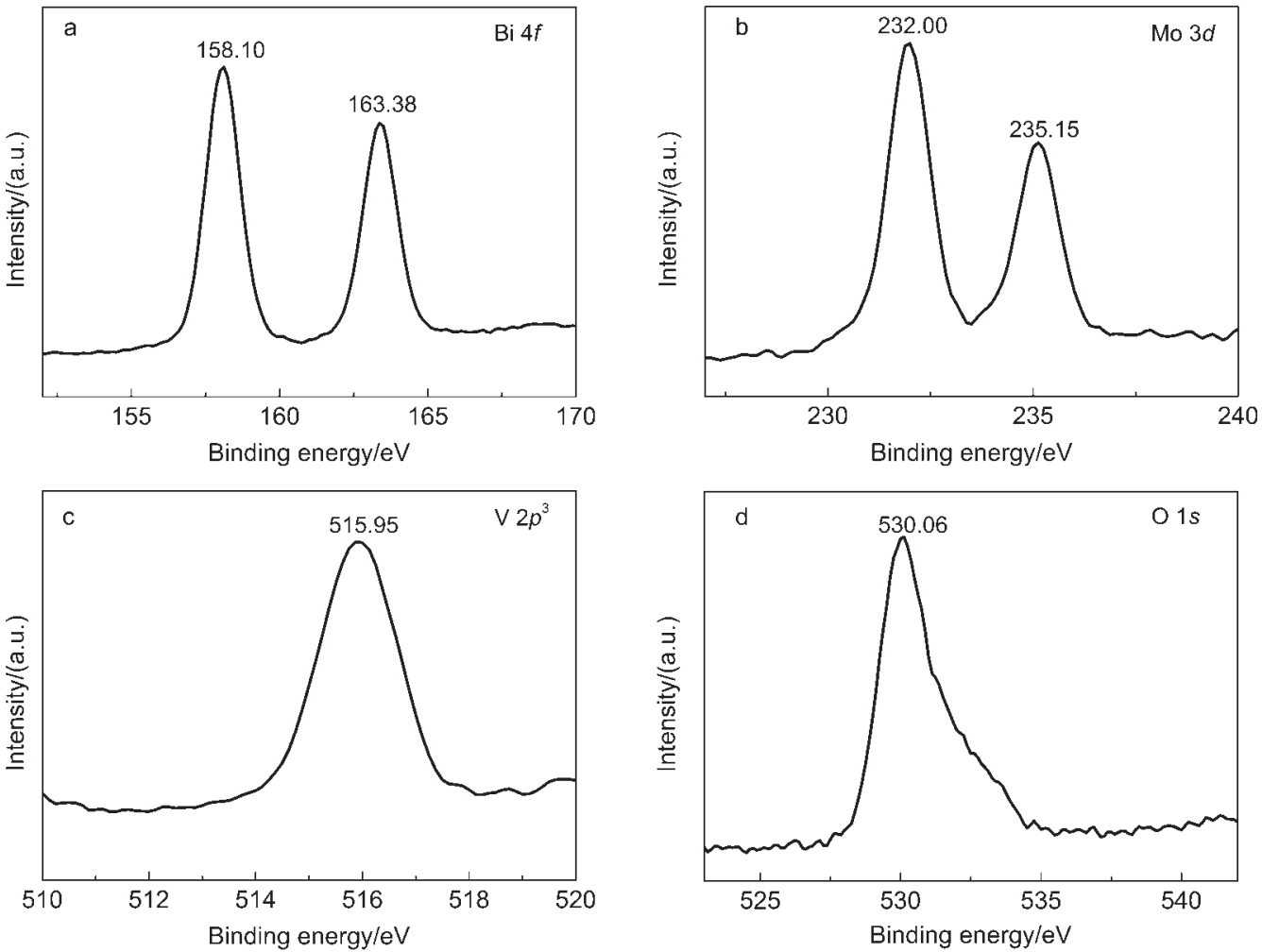

Fig.2 XPS spectra of $\mathrm{Bi}_{2} \mathrm{MoO}_{6} / \mathrm{BiVO}_{4}-\mathrm{HT}$ sample
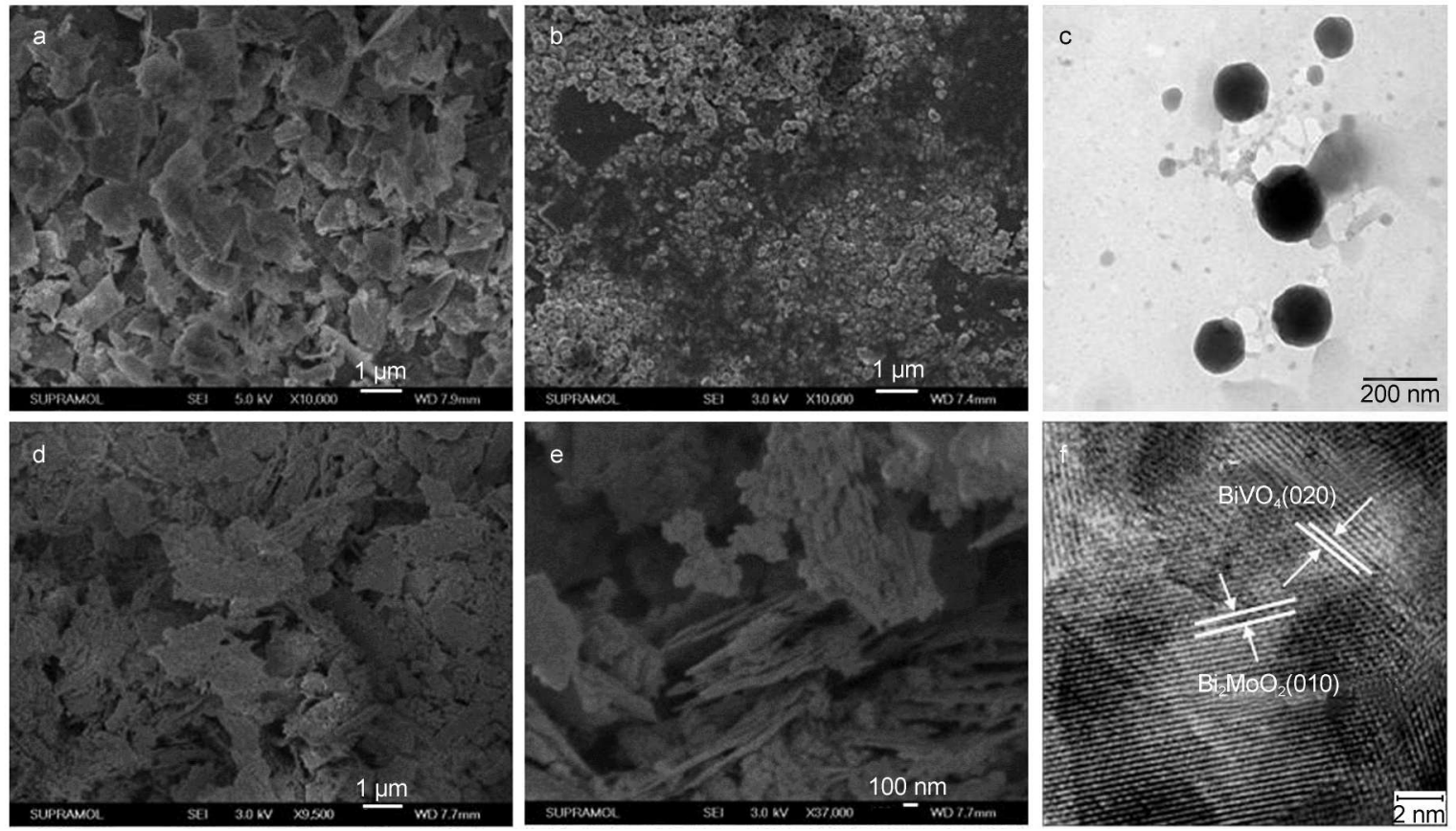

Fig.3 FESEM and TEM images of the as-prepared samples

(a) FESEM image of $\mathrm{BiVO}_{4}$, (b) FESEM image of $\mathrm{Bi}_{2} \mathrm{MoO}_{6}$, (c) TEM image of $\mathrm{Bi}_{2} \mathrm{MoO}_{6}$, (d, e) FESEM image of $\mathrm{Bi}_{2} \mathrm{MoO}_{6} / \mathrm{BiVO}_{4}-\mathrm{HT}_{\text {, }}$ (f) HRTEM image of $\mathrm{Bi}_{2} \mathrm{MoO}_{6} / \mathrm{BiVO}_{4}-\mathrm{HT}$

culated to be about 1 , which is in accordance with the nominal molar ratio of $\mathrm{Bi}_{2} \mathrm{MoO}_{6}-\mathrm{BiVO}_{4}$ heterojunction.

\subsection{Specific surface areas and pore structure}

$\mathrm{N}_{2}$ adsorption-desorption isotherms were performed to determine the surface areas of the as-prepared samples, as shown in
Fig.4a. The as-fabricated samples exhibit a type-IV isotherm, which is a more efficient photocatalyst structure for degradating organic pollutants in water. The BET surface areas of as-synthesized $\mathrm{BiVO}_{4}, \mathrm{Bi}_{2} \mathrm{MoO}_{6}$, and $\mathrm{Bi}_{2} \mathrm{MoO}_{6} / \mathrm{BiVO}_{4}-\mathrm{HT}$ are 16.71 , 27.49 , and $29.82 \mathrm{~m}^{2} \cdot \mathrm{g}^{-1}$, respectively. The BET surface area of 

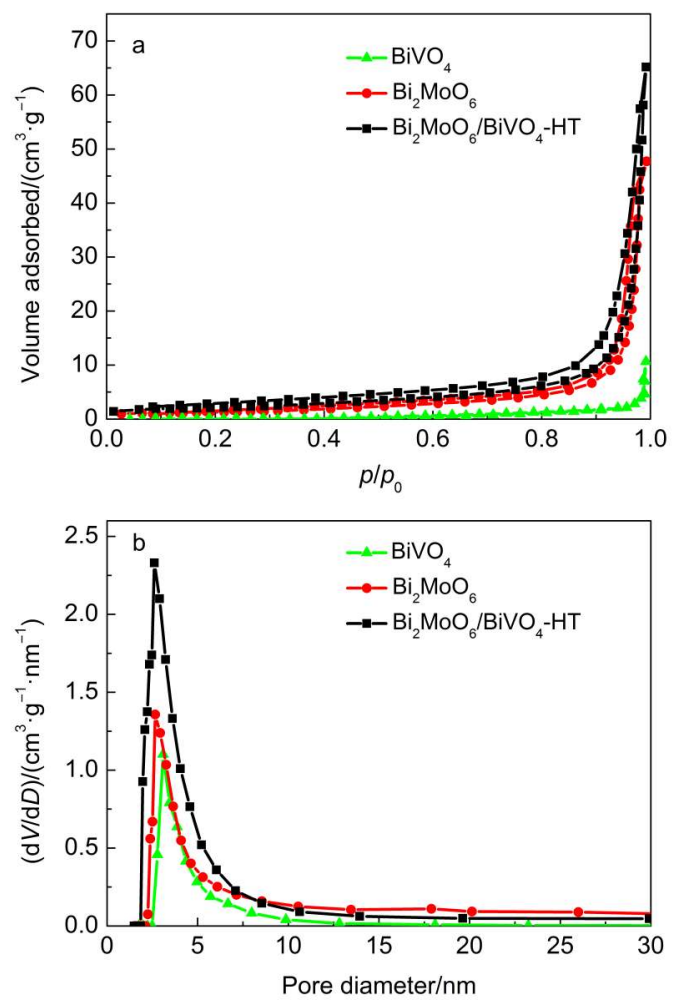

Fig.4 (a) $\mathrm{N}_{2}$ adsorption-desorption isotherm curves and (b) pore size distributions of different samples

$\mathrm{Bi}_{2} \mathrm{MoO}_{6} / \mathrm{BiVO}_{4}-\mathrm{HT}$ sample is the largest among these samples, which is attributed to the smaller grain size of $\mathrm{Bi}_{2} \mathrm{MoO}_{6} / \mathrm{BiVO}_{4-}$ HT. In addition, the corresponding pore size distribution curves for the as-prepared samples were obtained by the BJH method. It indicates a relative narrow pore size distribution centered at about $5 \mathrm{~nm}$ (as illustrated in Fig.4b). The larger BET surface area and porous structure can facilitate more efficient contact of $\mathrm{Bi}_{2} \mathrm{MoO}_{6} /$ $\mathrm{BiVO}_{4}$-HT with organic contaminants and thus improve its photocatalytic activity.

\subsection{UV-Vis diffuse reflectance spectra}

Fig.5a shows the UV-Vis diffuse reflectance spectra (DRS) of the photocatalysts. An absorption edge at about $490 \mathrm{~nm}$ is attributed to the band-band transition of $\mathrm{Bi}_{2} \mathrm{MoO}_{6}$. It is also shown that an absorption edge of $\mathrm{BiVO}_{4}$ is at $550 \mathrm{~nm}$. The spectrum of $\mathrm{Bi}_{2} \mathrm{MoO}_{6} / \mathrm{BiVO}_{4}$ heterojunction shows the combinations of the individual spectrum of $\mathrm{Bi}_{2} \mathrm{MoO}_{6}$ and $\mathrm{BiVO}_{4}$. A red shift of the absorption edge can be obviously observed. This phenomenon is comparable to those reported in the literature. ${ }^{33,34}$ It is believed that the enhancement in photonic absorption for the $\mathrm{Bi}_{2} \mathrm{MoO}_{6} / \mathrm{BiVO}_{4}{ }^{-}$ HT may be related to the partial leakage of multi excitons into both $\mathrm{Bi}_{2} \mathrm{MoO}_{6}$ and $\mathrm{BiVO}_{4}$ matrix due to formation of $\mathrm{Bi}_{2} \mathrm{MoO}_{6} /$ $\mathrm{BiVO}_{4}-\mathrm{HT}^{35,36}$

The band gap energies $\left(E_{\mathrm{g}}\right)$ of $\mathrm{Bi}_{2} \mathrm{MoO}_{6}$ and $\mathrm{BiVO}_{4}$ can be calculated by the following formula: $:^{35}$

$$
\alpha h v=A\left(h v-E_{\mathrm{g}}\right)^{n / 2}
$$

where $\alpha, v$, and $A$ are absorption coefficient, the light frequency, and a constant, respectively. Among these parameters, $n$ is de-
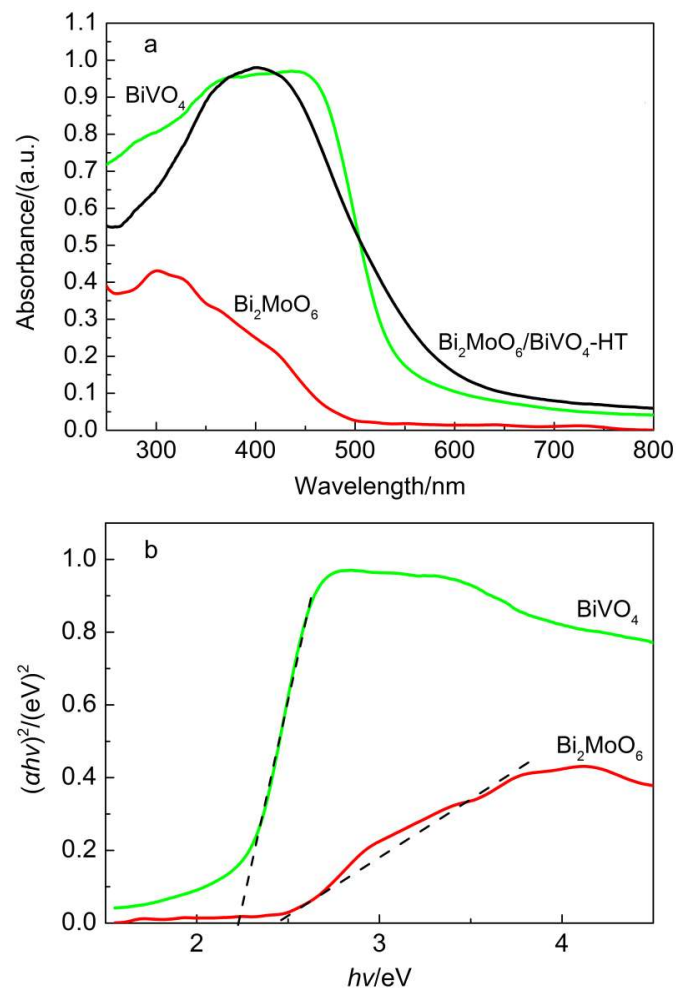

Fig.5 (a) UV-Vis DRS of $\mathrm{BiVO}_{4}, \mathrm{Bi}_{2} \mathrm{MoO}_{6}$ and $\mathrm{Bi}_{2} \mathrm{MoO}_{6} / \mathrm{BiVO}_{4}-$

HT and (b) plots of $(\alpha h v)^{2}$ versus energy (hv) for the band gap energies of $\mathrm{BiVO}_{4}$ and $\mathrm{Bi}_{2} \mathrm{MoO}_{6}$

termined by the type of optical transition of a semiconductor ( $n=$ 1 for a direct transition and $n=4$ for an indirect transition). For $\mathrm{BiVO}_{4}$ and $\mathrm{Bi}_{2} \mathrm{MoO}_{6}$, the values of $n$ are 1 for the direct transition. ${ }^{37,38}$ According to Eq.(1), the band gap energies of $\mathrm{Bi}_{2} \mathrm{MoO}_{6}$ and $\mathrm{BiVO}_{4}$ can be estimated from a plot of $(\alpha h v)^{2}$ versus energy $(h v)$. Thus, the band gap energies of the as-prepared $\mathrm{Bi}_{2} \mathrm{MoO}_{6}$ and $\mathrm{BiVO}_{4}$ are estimated to be 2.50 and $2.24 \mathrm{eV}$, respectively (as illustrated in Fig.5b).

\subsection{Photocatalytic activity}

Compared to pure $\mathrm{BiVO}_{4}$ and $\mathrm{Bi}_{2} \mathrm{MoO}_{6}$, there are some changes in the electronic structure of $\mathrm{Bi}_{2} \mathrm{MoO}_{6} / \mathrm{BiVO}_{4}-\mathrm{HT}$. After this phenomenon was confirmed, its photocatalytic performance was evaluated by decolorizing $\mathrm{RhB}$ under visible-light irradiation, and the results are shown in Fig.6. The temporal evolutions of the spectral changes during the photodegradation of $\mathrm{RhB}$ over $\mathrm{Bi}_{2} \mathrm{MoO}_{6} / \mathrm{BiVO}_{4}-\mathrm{HT}$ under visible-light illumination are displayed in Fig.6a. It was found that the absorbance is gradually decreased along with a slight blue shift in $\lambda_{\max }$ during visible light irradiation. The photodegradation for the three kinds of photocatalysts is shown in Fig.6b. The photolysis test demonstrates that the selfdegradation of $\mathrm{RhB}$ was extremely slow, only $2 \%$ of $\mathrm{RhB}$ was photolyzed after $40 \mathrm{~min}$ of visible light irradiation. It can be seen that the removal rate of $\mathrm{RhB}$ concentration in the present of pure $\mathrm{BiVO}_{4}$ was about $80 \%$ in 40 min under visible light irradiation. In the presence of pure $\mathrm{Bi}_{2} \mathrm{MoO}_{6}$, the removal efficiency of $\mathrm{RhB}$ was $90 \%$ within 40 min of irradiation. However, with $\mathrm{Bi}_{2} \mathrm{MoO}_{6} / \mathrm{BiVO}_{4}$ HT as photocatalyst, nearly $100 \%$ of the RhB was decolorized 

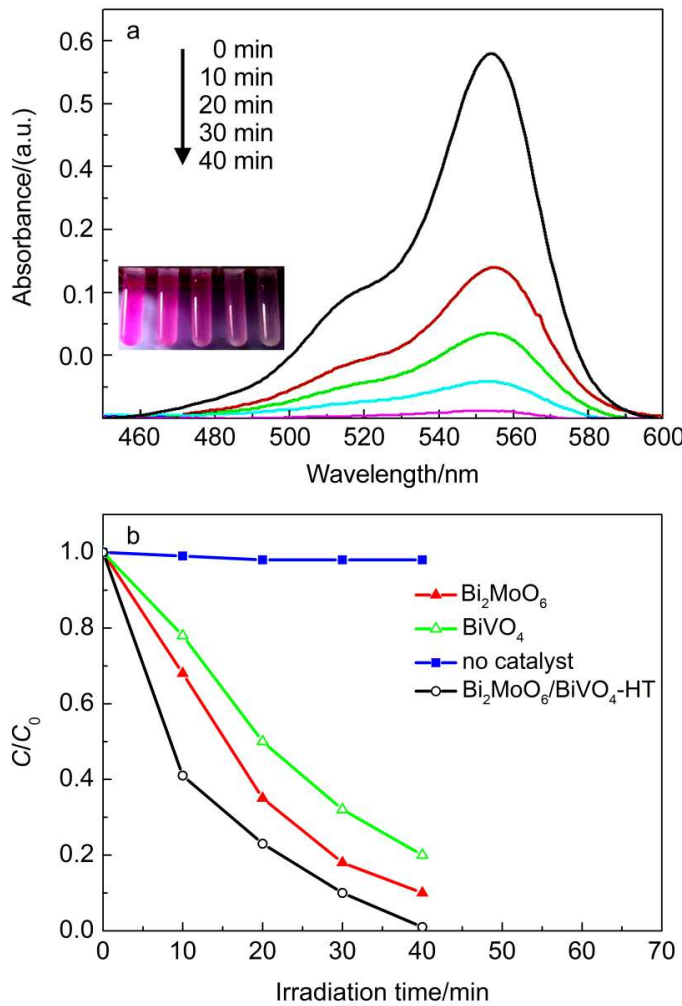

Fig.6 (a) UV-Vis spectra, corresponding colors of RhB over $\mathrm{Bi}_{2} \mathrm{MoO}_{6} / \mathrm{BiVO}_{4}-\mathrm{HT}$ sample and (b) photodegradation efficiencies of RhB as a function of irradiation time for different photocatalysts

after 40 min, showing a high photocatalytic activity under visiblelight irradiation. The as-prepared $\mathrm{Bi}_{2} \mathrm{MoO}_{6} / \mathrm{BiVO}_{4}-\mathrm{HT}$ sample revealed a higher photocatalytic activity, compared with pure $\mathrm{Bi}_{2} \mathrm{MoO}_{6}$ and $\mathrm{BiVO}_{4}$. It indicates that the large enhancement of the removal rate can be attributed the heterojunction generated by the loading of $\mathrm{Bi}_{2} \mathrm{MoO}_{6}$ on the $\mathrm{BiVO}_{4}$ particles, intensive absorption within the visible light range, and high specific surface area.

In a photocatalytic reaction, the activity is largely affected by the recombination of the photoinduced electrons and holes, which will decrease the quantum yield. ${ }^{39}$ It is known that the recombination of photogenerated hole-electron pairs can release energy in the form of fluorescence emission. Lower fluorescence emission intensity shows lower electron-hole recombination rate and corresponds to higher photocatalytic activity. To study the recombination of electron-hole pairs in photocatalysis, $\mathrm{PL}$ emission spectra of $\mathrm{BiVO}_{4}, \mathrm{Bi}_{2} \mathrm{MoO}_{6}$, and $\mathrm{Bi}_{2} \mathrm{MoO}_{6} / \mathrm{BiVO}_{4}$ - $\mathrm{HT}$ were measured, as shown in Fig.7. The emission intensities of pure $\mathrm{BiVO}_{4}$ and $\mathrm{Bi}_{2} \mathrm{MoO}_{6}$ are stronger than that of $\mathrm{Bi}_{2} \mathrm{MoO}_{6} / \mathrm{BiVO}_{4}-\mathrm{HT}$, indicating that the electron-hole pairs of pure $\mathrm{BiVO}_{4}$ and $\mathrm{Bi}_{2} \mathrm{MoO}_{6}$ recombine rapidly, while the electron-hole pair recombination rate of $\mathrm{Bi}_{2} \mathrm{MoO}_{6} / \mathrm{BiVO}_{4}-\mathrm{HT}$ is greatly decreased. It suggests that the heterojunction of $\mathrm{Bi}_{2} \mathrm{MoO}_{6} / \mathrm{BiVO}_{4}$ further improves the charge separation and efficient interelectron transfer.

It is worth pointing out that the stability of a given photocatalyst during photoreaction is a crucial factor for any practical applications. To test the stability of $\mathrm{Bi}_{2} \mathrm{MoO}_{6} / \mathrm{BiVO}_{4}-\mathrm{HT}$, the heterojunction was reused three times as shown in Fig.8. After

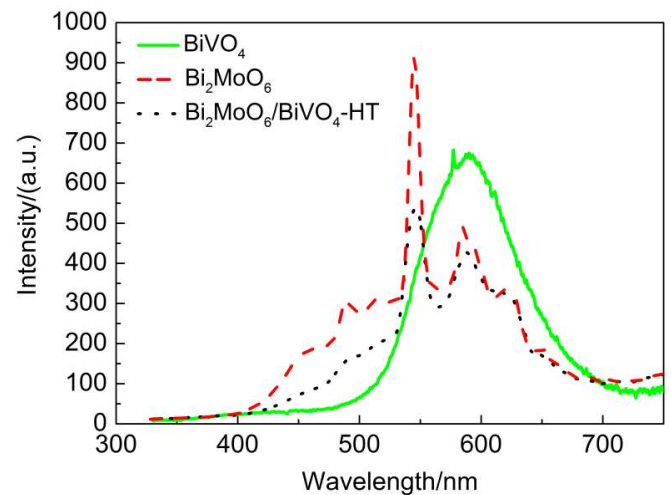

Fig.7 PL spectra of pure $\mathrm{BiVO}_{4}, \mathrm{Bi}_{2} \mathrm{MoO}_{6}$, and $\mathrm{Bi}_{2} \mathrm{MoO}_{6} / \mathrm{BiVO}_{4}$ $\mathrm{HT}$ under the excitation wavelength of $325 \mathrm{~nm}$ at room temperature

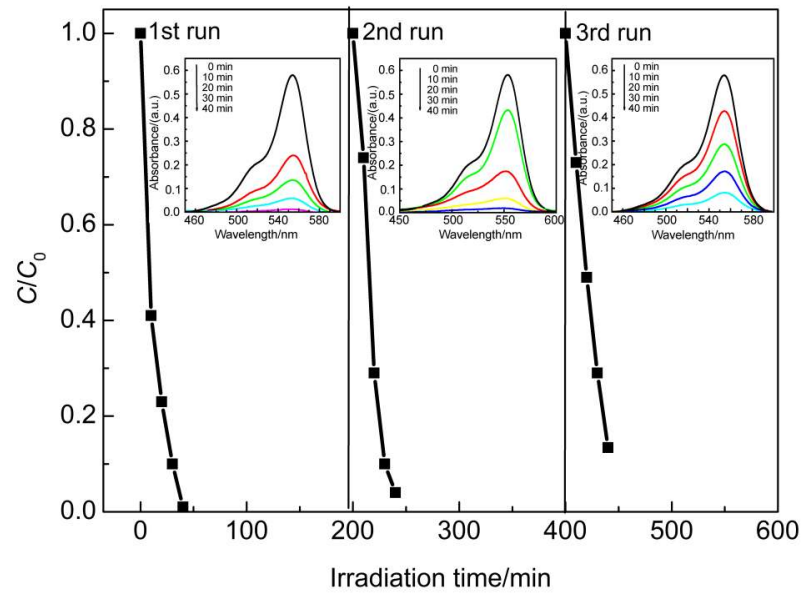

Fig.8 Cycling runs for the photocatalytic degradation of RhB over $\mathrm{Bi}_{2} \mathrm{MoO}_{6} / \mathrm{BiVO}_{4}-\mathrm{HT}$ under visible light irradiation

reusing three cycles, the photodecomposition rate of $\mathrm{RhB}$ still remains over $85 \%$, indicating that $\mathrm{Bi}_{2} \mathrm{MoO}_{6} / \mathrm{BiVO}_{4}-\mathrm{HT}$ can be deemed as an attractive candidate for industrial water purification.

\subsection{Discussion of the mechanism}

The above results reveal that the formation of heterojunction combining $\mathrm{Bi}_{2} \mathrm{MoO}_{6}$ with $\mathrm{BiVO}_{4}$ can enhance its photocatalytic activity under visible light irradiation. On the basis of experimental results, a possible visible light photocatalytic mechanism

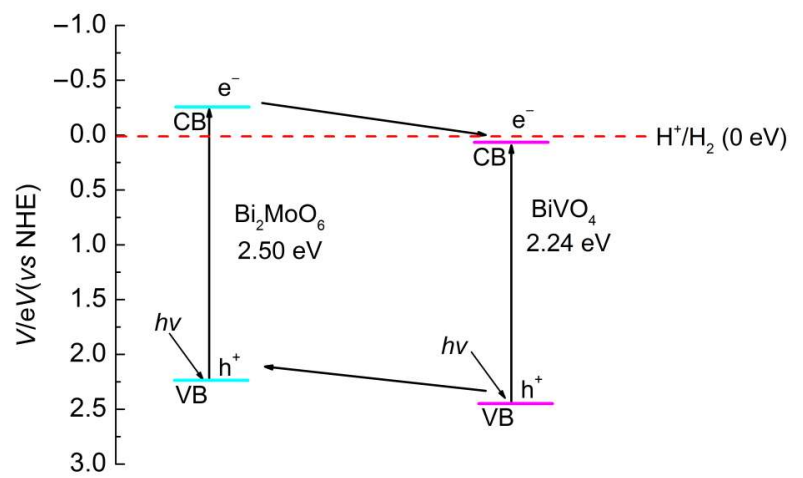

Fig.9 Schematic diagram of the separation and transfer of photogenerated charges in the $\mathrm{Bi}_{2} \mathrm{MoO}_{6} / \mathrm{BiVO}_{4}$ composite under visible light irradiation 
of the $\mathrm{Bi}_{2} \mathrm{MoO}_{6} / \mathrm{BiVO}_{4}$ heterojunction is proposed, as shown in Fig.9. The conduction band potentials of $\mathrm{Bi}_{2} \mathrm{MoO}_{6}$ and $\mathrm{BiVO}_{4}$, were estimated based on the equation of $E_{\mathrm{CB}}=X-E^{\mathrm{e}}-1 / 2 E_{\mathrm{g}}$, where $X$ is the electronegativity of the semiconductor, $E^{\mathrm{e}}$ is the energy of free electrons on the hydrogen scale (ca $4.5 \mathrm{eV}$ ), $E_{\mathrm{g}}$ is the band gap energy of the semiconductor. Based on the equation of $E_{\mathrm{VB}}=$ $E_{\mathrm{CB}}+E_{\mathrm{g}}$, the valence band edge energy of a semiconductor can be predicted by Mulliken electronegativity theory. It can be seen that the calculated positions of $\mathrm{CB}$ and $\mathrm{VB}$ edge potentials of $\mathrm{Bi}_{2} \mathrm{MoO}_{6}$ are determined to be -0.25 and $2.25 \mathrm{eV}$, respectively. For $\mathrm{BiVO}_{4}$, the $\mathrm{CB}$ and VB potentials are calculated to be 0.08 and $2.32 \mathrm{eV}$, respectively. The conduction band and valence band potentials of $\mathrm{Bi}_{2} \mathrm{MoO}_{6}(-0.25$ and $2.25 \mathrm{eV}$, respectively) are more negative than those of $\mathrm{BiVO}_{4}(0.08$ and $2.32 \mathrm{eV}$, respectively), suggesting that $\mathrm{Bi}_{2} \mathrm{MoO}_{6}$ and $\mathrm{BiVO}_{4}$ match the band potentials in the $\mathrm{Bi}_{2} \mathrm{MoO}_{6} /$ $\mathrm{BiVO}_{4}$ heterojunction. Once the heterojunction is irradiated by visible light, both $\mathrm{Bi}_{2} \mathrm{MoO}_{6}$ and $\mathrm{BiVO}_{4}$ can be excited and produce photogenerated electron-hole pairs. Due to the well-matched overlapping band-structures and intimate interfaces (see Fig.2f), photogenerated electrons on the $\mathrm{CB}$ of $\mathrm{Bi}_{2} \mathrm{MoO}_{6}$ can easily transfer to the $\mathrm{CB}$ of $\mathrm{BiVO}_{4}$, and on the contrary, holes on the $\mathrm{VB}$ of $\mathrm{BiVO}_{4}$ spontaneously move to the $\mathrm{VB}$ of $\mathrm{Bi}_{2} \mathrm{MoO}_{6}$. This transference effectively suppresses the charge recombination, and thus results in an enhanced photocatalytic activity.

Another series of tests were designed to probe the photocatalytic oxidation process. As displayed in Fig. 10, with $2 \mathrm{mmol}$ of $t$ $\mathrm{BuOH}$ as a $\mathrm{OH} \cdot$ radical scavenger added to the solution, ${ }^{38}$ the degradation rate of $\mathrm{RhB}$ over $\mathrm{Bi}_{2} \mathrm{MoO}_{6} / \mathrm{BiVO}_{4}-\mathrm{HT}$ sample had no obvious change, indicating that $\mathrm{OH} \cdot$ was not reactive species involved in the degradation of $\mathrm{RhB}$ process. When $2 \mathrm{mmol}$ of EDTA-2Na as a $\mathrm{h}^{+}$scavenger was added, ${ }^{40}$ there was decrease of degradation rate, showing the $\mathrm{h}^{+}$was involved. However, with the addition of $2 \mathrm{mmol}$ of $\mathrm{O}_{2}^{-}$scavenger $\mathrm{BQ},{ }^{39}$ the degradation of $\mathrm{RhB}$ was significantly prohibited, suggesting that the $\mathrm{O}_{2}^{-}$pathways have a crucial role in the process of $\mathrm{RhB}$ oxidation.

On the basis of the band gap structure of $\mathrm{Bi}_{2} \mathrm{MoO}_{6} / \mathrm{BiVO}_{4}$ composite and the effects of scavengers, a possible pathway for the photocatalytic degradation of $\mathrm{RhB}$ with $\mathrm{Bi}_{2} \mathrm{MoO}_{6} / \mathrm{BiVO}_{4}$ photocatalyst is proposed as follows:

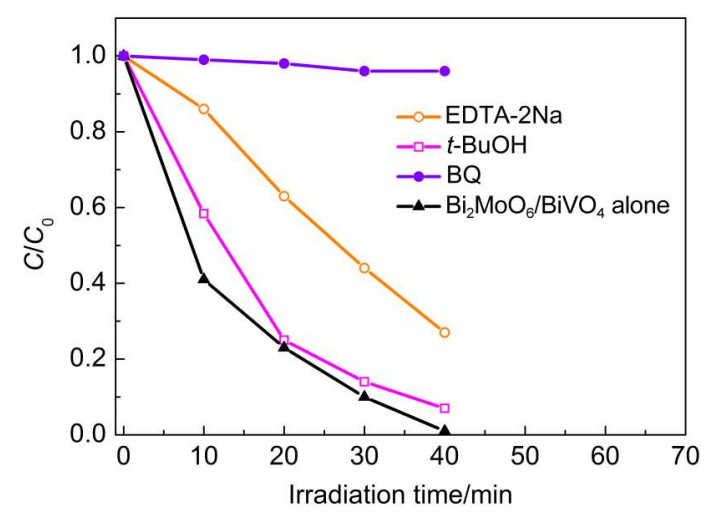

Fig.10 Photocatalytic degradation of $\mathrm{RhB}$ over $\mathrm{Bi}_{2} \mathrm{MoO}_{6} / \mathrm{BiVO}_{4}$ composite alone and the addition of $t$-BuOH, EDTA, or BQ

$$
\begin{aligned}
& \mathrm{Bi}_{2} \mathrm{MoO}_{6}+h v \rightarrow \mathrm{Bi}_{2} \mathrm{MoO}_{6}\left(\mathrm{~h}_{\mathrm{VB}}^{+}\right)+\mathrm{Bi}_{2} \mathrm{MoO}_{6}\left(\mathrm{e}^{-}\right) \\
& \mathrm{BiVO}_{4}+h v \rightarrow \mathrm{BiVO}_{4}\left(\mathrm{~h}_{\mathrm{VB}}^{+}\right)+\mathrm{BiVO}_{4}\left(\mathrm{e}^{-}\right) \\
& \mathrm{BiVO}_{4}\left(\mathrm{e}^{-}\right)+\mathrm{O}_{2} \rightarrow \mathrm{O}_{2}^{-} \\
& \mathrm{h}_{\mathrm{VB}}^{+}+\mathrm{O}_{2}^{-}+\mathrm{RhB} \rightarrow \text { products }
\end{aligned}
$$

The CB electrons $\left(\mathrm{e}^{-}\right)$accumulated on the surface of $\mathrm{BiVO}_{4}$ were then scavenged by oxygen on the surface of the catalyst to form super oxide radicals $\left(\mathrm{O}_{2}^{-}{ }^{-}\right)$, which could react with $\mathrm{RhB}$ molecules. In addition, holes in the $\mathrm{Bi}_{2} \mathrm{MoO}_{6}$ might directly oxidize the $\mathrm{RhB}$ through the direct hole oxidation process. Therefore, the photogenerated electron-hole pairs were separated effectively through the heterojunction interface formed in the $\mathrm{Bi}_{2} \mathrm{MoO}_{6} /$ $\mathrm{BiVO}_{4}$ composite, and more electrons and holes could transfer to the surface of the composite and join in the surface reaction. In addition, the strong visible light absorption, larger BET surface area and porous structure were also favorable for the photocatalytic activity enhancement of $\mathrm{Bi}_{2} \mathrm{MoO}_{6} / \mathrm{BiVO}_{4}$ composite.

\section{Conclusions}

In summary, we have successfully developed a $\mathrm{Bi}_{2} \mathrm{MoO}_{6} / \mathrm{BiVO}_{4}$ heterojunction via a hydrothermal method. The resulting $\mathrm{Bi}_{2} \mathrm{MoO}_{6}$ $\mathrm{BiVO}_{4}$ composite owned a strong absorption in the visible light region and had obviously enhanced photocatalytic activity for the degradation of $\mathrm{RhB}$. This enhancement could be attributed to the high separation and easy transfer of photogenerated electron-hole pairs at the intimate interface of heterojunctions, which can be reasonably ascribed to the well-aligned overlapping band-structures of $\mathrm{Bi}_{2} \mathrm{MoO}_{6}$ and $\mathrm{Bi}_{2} \mathrm{MoO}_{6}$. Moreover, the composite photocatalyst depicted an extreme stability that the photodecomposition rate of $\mathrm{RhB}$ still remained over $85 \%$ after three cycles.

\section{References}

(1) Hu, Y. F.; Li, Y. X.; Peng, S. Q.; Lü, G. X.; Li, S. B. Acta Phys. -Chim. Sin. 2008, 24 (11), 2071. [胡元方, 李越湘, 彭绍 琴, 吕功煊, 李树本. 物理化学学报, 2008, 24 (11), 2071.] doi: 10.3866/PKU.WHXB20081123

(2) Mao, Y. B.; Wong, S. S. J. Am. Chem. Soc. 2006, 128, 8217. doi: 10.1021/ja0607483

(3) Li, B. X.; Wang, Y. F.; Liu, T. X. Acta Phys. -Chim. Sin. 2011, 27 (12), 2946. [李本侠, 王艳芬, 刘同宣. 物理化学学报, 2011, 27 (12), 2946.] doi: 10.3866/PKU.WHXB20112946

(4) Fujishima, A.; Honda, K. Nature 1972, 238, 37. doi: 10.1038/ $238037 \mathrm{a} 0$

(5) Lu, S. Y.; Wu, D.; Wang, Q. L.; Yan, J. H.; Buekens, A. G.; Cen, K. F. Chemosphere 2011, 82, 1215. doi: 10.1016/j. chemosphere.2010.12.034

(6) Huang, C. X.; Zhu, K. R.; Qi, M. Y.; Zhuang, Y. L.; Cheng, C. J. Phys. Chem. Solids 2012, 73, 757.

(7) Hasanpour, A.; Niyaifar, M.; Mohammadpour, H.; Amighian, J. J. Phys. Chem. Solids 2012, 73, 1066. doi: 10.1016/j. jpcs.2012.04.003

(8) Lin, Y.; Geng, Z. G.; Cai, H. B.; Ma, L.; Chen, J.; Zeng, J.; Pan, N.; Wang, X. Q. Eur. J. Inorg. Chem. 2012, 28, 4439. 
(9) Dai, Y. Q.; Jing, Y.; Zeng, J.; Qi, Q.; Wang, C. L.; Goldfeld, D.; Xu, C. H.; Zheng, Y. P.; Sun, Y. M. J. Mater. Chem. 2011, 21, 18174. doi: $10.1039 / \mathrm{c} 1 \mathrm{jm} 13641 \mathrm{k}$

(10) Yan, Y.; Sun, S. F.; Song, Y.; Yan, X.; Guan, W. S.; Liu, X. L.; Shi, W. D. J. Hazard. Mater. 2013, 250-251, 106.

(11) Wang, X. K.; Li, G. C.; Ding, J.; Peng, H. R.; Chen, K. Z. Mater. Res. Bull. 2012, 47, 3814. doi: 10.1016/j.materresbull. 2012.04 .082

(12) Lin, X.; Li, H. J.; Yu, L. L.; Zhao, H.; Yan, Y. S.; Liu, C. B.; Zhai, H. J. Mater. Res. Bull. 2013, 48, 4424. doi: 10.1016/j. materresbull.2013.06.075

(13) Lin, X.; Lv, P.; Guan, Q. F.; Li, H. B.; Zhai, H. J.; Liu, C. B. Appl. Surf. Sci. 2012, 258, 7146. doi: 10.1016/j. apsusc.2012.04.019

(14) Zhang, L. W.; Wang, Y. J.; Cheng, H. Y.; Yao, W. Q.; Zhu, Y. F. Adv. Mater. 2009, 21, 1286. doi: 10.1002/adma.v21:12

(15) Zhuo, Y. Q.; Huang, J. F.; Cao, L. Y.; Ouyang, H. B.; Wu, J. P. Mater. Lett. 2013, 90, 107. doi: 10.1016/j.matlet.2012.09.009

(16) Tian, G. H.; Chen, Y. J.; Meng, X. Y.; Zhou, J.; Zhou, W.; Pan, K.; Tian, C. G.; Ren, Z. Y.; Fu, H. G. ChemPlusChem 2013, 78 , 117. doi: $10.1002 /$ cplu. 201200198

(17) Zhang, A. P.; Zhang, J. Z. Appl. Surf. Sci. 2010, 256, 3224. doi: 10.1016/j.apsusc.2009.12.009

(18) Cao, S. W.; Yin, Z.; Barber, J.; Boey, F. Y. C.; Loo, S. C. J.; Xue, C. ACS Appl. Mater. Interfaces 2012, 4, 418. doi: 10.1021/ am201481b

(19) Zhang, J. Y.; Wang, Y. H.; Zhang, J.; Lin, Z.; Huang, F.; Yu, J. G. ACS Appl. Mater. Interfaces 2013, 5, 1031. doi: 10.1021/ am302726y

(20) Yuan, B.; Wang, C. H.; Qi, Y.; Song, X. L.; Mu, K.; Guo, P.; Meng, L. T. Colloid Surface A 2013, 425, 99. doi: 10.1016/j. colsurfa.2013.02.058

(21) Ge, L.; Liu, J. Mater. Lett. 2011, 65, 1828. doi: 10.1016/j. matlet.2011.03.066

(22) Chatchai, P.; Kishioka, S. Y.; Murakami, Y.; Nosaka, A. Y.; Nosaka, Y. Electrochimica Acta 2010, 55, 592. doi: 10.1016/j. electacta.2009.09.032

(23) Zhang, X. F.; Gong, Y.; Dong, X. L.; Zhang, X. X.; Ma, C.; Shi, F. Mater. Chem. Phys. 2012, 136, 472. doi: 10.1016/j. matchemphys.2012.07.013

(24) Zhang, F. J.; Zhu, S. F.; Xie, F. Z.; Zhang, J.; Meng, Z. D. Sep
Purif. Technol. 2013, 113, 1. doi: 10.1016/j.seppur.2013.04.008

(25) Tian, Y. L.; Chang, B. B.; Lu, J. L.; Fu, J.; Xi, F. N.; Dong, X. P. ACS Appl. Mater. Interfaces 2013, 5, 7079. doi: 10.1021/ am4013819

(26) Wang, S.; Yi, L. X.; Halpert, J. E.; Lai, X. Y.; Liu, Y. Y.; Cao, H. B.;Yu, R. B.; Wang, D.; Li, Y. L. Small 2012, 8, 265. doi: 10.1002/smll.v8.2

(27) Du, J.; Lai, X. Y.; Yang, N. L.; Zhai, J.; Kisailus, D.; Su, F. B.; Wang, D.; Jiang, L. ACS Nano 2011, 5, 590. doi: 10.1021/ nn102767d

(28) Yang, N. L.; Liu, Y. Y.; Wen, H.; Tang, Z. Y.; Zhao, H. J.; Li, Y. L.; Wang, D. ACS Nano 2013, 7, 1504. doi: 10.1021/nn305288z

(29) Yu, C. L.; Li, G.; Kumar, S.; Yang, K.; Jin, R. C. Adv. Mater. 2014, 26, 892

(30) Sun, Y.; Xie, Y.; Wu, C.; Long, R. Cryst. Growth Des. 2010, 10, 602. doi: $10.1021 / \mathrm{cg} 900988 \mathrm{j}$

(31) Shang, M.; Wang, W. Z.; Sun, S. M.; Ren, J.; Zhou, L.; Zhang, L. J. Phys. Chem. C 2009, 113, 20228. doi: 10.1021/jp9067729

(32) Wu, S. Y.; Zheng, H.; Lian, Y. W.; Wu, Y. Y. Mater. Res. Bull. 2013, 48, 2901. doi: 10.1016/j.materresbull.2013.04.041

(33) Yan, H. J.; Yang, H. X. J. Alloy. Compd. 2011, 509, L26.

(34) Xu, H.; Yan, J.; Xu, Y. G.; Song, Y. H.; Li, H. M.; Xia, J. X.; Huang, C. J.; Wan, H. L. Appl. Catal. B: Environ. 2013, 129, 182. doi: $10.1016 /$ j.apcatb.2012.08.015

(35) Li, T. T.; Zhao, L. H.; He, Y. M.; Cai, J.; Luo, M. F.; Lin, J. J. Appl. Catal. B: Environ. 2013, 129, 255. doi: 10.1016/j. apcatb.2012.09.031

(36) Wang, S. M.; Li, D. L.; Sun, C.; Yang, S. G.; Guan, Y.; He, H. Appl. Catal. B: Environ. 2014, 144, 885. doi: 10.1016/j. apcatb.2013.08.008

(37) Lin, X.; Yu, L. L.; Yan, L. N.; Li, H. J.; Yan, Y. S.; Liu, C. B.; Zhai, H. J. Solid State Sci. 2014, 32, 61. doi: 10.1016/j. solidstatesciences.2014.03.018

(38) Zhang, M. Y.; Shao, C. L.; Mu, J. B.; Zhang, Z. Y.; Guo, Z. C.; Zhang, P.; Liu, Y. C. CrystEngComm 2012, 14, 605. doi: 10.1039/c1ce05974b

(39) Jiang, D. L.; Chen, L. L.; Zhu, J. J.; Chen, M.; Shi, W. D.; Xie, J. M. Dalton Trans. 2013, 42, 15726. doi: 10.1039/c3dt52008k

(40) Zhang, S. Q.; Yang, Y. X.; Guo, Y. N.; Guo, W.; Wang, M.; Guo, Y. H.; Huo, M. X. J. Hazard. Mater. 2013, 261, 235. doi: 10.1016/j.jhazmat.2013.07.025 